\title{
Use of a Shared Canister Protocol for the Delivery of Metered-Dose Inhalers in Mechanically Ventilated Subjects
}

\author{
Mollie Gowan PharmD, Jennifer Bushwitz PharmD, Peggy Watts RRT, Patty C Silver MEd RRT, \\ Mark Jackson MPPA, Nicholas Hampton PharmD, and Marin H Kollef MD
}

\begin{abstract}
BACKGROUND: Mechanically ventilated patients often need bronchodilators administered via a metered-dose inhaler (MDI). Unfortunately, there are no data examining the impact of shared canister delivery of MDI therapy in mechanically ventilated patients. METHODS: A prospective trial was conducted with subjects assigned to shared canister MDI therapy or single-patient canister MDI therapy. Outcomes assessed were occurrence of ventilator-associated pneumonia (VAP), hospital mortality, length of stay, ventilator-associated events, and MDI costs. RESULTS: Among 486 screened patients, 353 were included for analysis of which $201(56.9 \%)$ received shared canister MDI therapy and $152(43.1 \%)$ received single-patient canister therapy. VAP $(7.0 \%$ vs $4.6 \%, P=.35)$, hospital mortality (21.9\% vs $20.4 \%, P=.73$ ), and ventilator days (median [interquartile range] 3.1 [0.9-7.5] d vs 2.7 $[1.2-7.1] \mathrm{d}, P=.62)$ were similar between the shared canister and single-patient canister groups. We did not observe clinically important differences for ventilator-associated events between study groups in our logistic regression analysis $(P=.07)$. There was a savings of $\$ 217 /$ subject in the shared canister group due to the use of 299 fewer MDIs. CONCLUSIONS: Our study found that shared canister MDI therapy compared with single-patient MDI use was associated with a significant cost savings and similar rates of VAP, hospital mortality, and length of stay but a greater prevalence of ventilatorassociated events. This finding suggests that shared canister delivery of MDIs may be a cost-effective practice in mechanically ventilated patients. Based on our findings, further studies examining the overall safety of shared canister use in mechanically ventilated patients seem warranted before recommending their routine use. (ClinicalTrials.gov registration NCT01935388.) Key words: mechanical ventilation; common canister; outcome. [Respir Care 2016;61(10):1285-1292. () 2016 Daedalus Enterprises]
\end{abstract}

\section{Introduction}

The need for mechanical ventilation is one of the most common indications for admission to an ICU. Moreover,

\footnotetext{
Drs Gowan and Bushwitz are affiliated with the Department of Pharmacy, Barnes-Jewish Hospital, St. Louis, Missouri. Ms Watts, Ms Silver, and Mr Jackson are affiliated with the Department of Respiratory Care Services, Barnes-Jewish Hospital, St. Louis, Missouri. Dr Hampton is affiliated with the Center for Clinical Excellence, BJC HealthCare, St. Louis, Missouri. Dr Kollef is affiliated with the Division of Pulmonary and Critical Care Medicine, Washington University School of Medicine, St Louis, Missouri.
}

This work was supported by the Barnes-Jewish Hospital Foundation. The authors have disclosed no conflicts of interest.

Correspondence: Marin H Kollef MD, Division of Pulmonary and Critical Care Medicine, Washington University School of Medicine, 4523 Clayton Avenue, Campus Box 8052, St. Louis, MO 63110. E-mail: mkollef@dom.wustl.edu.

DOI: $10.4187 /$ respcare. 04550 mechanically ventilated patients frequently receive aerosolized medication therapy administered via metered-dose inhalers (MDIs), as opposed to nebulization, to reduce costs, prevent patient-ventilator asynchrony, and minimize aerosol dispersion in the ICU during respiratory virus season. ${ }^{1}$ The currently accepted practice is to provide singlepatient MDI therapy during mechanical ventilation to minimize the risk of adverse events, such as nosocomial infections. Because most patients will not use the entire contents of an MDI during their hospitalization, most of the MDI capacity is discarded without clinical use. Unfortunately, there are no available studies to determine the most cost-effective method for the use of MDIs in ventilated patients.

Previous studies have demonstrated that ventilator circuits can be employed safely without routine changing of the circuit. ${ }^{2-4}$ Similarly, it has been shown that both in-line suction catheters ${ }^{5,6}$ and heat and moisture exchangers 7,8 can be employed for more prolonged time periods without 
increasing the risk of nosocomial infection or other adverse outcomes, although these are not shared between patients. The lack of data on how MDIs should most effectively be employed in the ICU served as the justification for this investigation. We planned to carry out a prospective trial comparing the usual practice of single-patient MDI therapy with a shared canister practice, whereby a single MDI is repetitively employed on different patients until it is fully discharged. The main goal of this trial was to assess the safety and clinical outcomes associated with shared canister inhalation therapy in mechanically ventilated subjects.

\section{Methods}

\section{Study Design and Ethical Standards}

The study was conducted at Barnes-Jewish Hospital, a 1,250-bed urban hospital in St. Louis, Missouri. During a 12-month period (April 15, 2014, through March 31, 2015), hospitalized patients in the medical ICU (34 beds) and the surgical ICU ( 36 beds) requiring mechanical ventilation and MDI therapy with albuterol, ipratropium, or ipratropium/albuterol were evaluated. The Washington University Human Research Protection Office approved the protocol, and the requirement for informed consent was waived (Human Research Protection Office number 201302130).

All patients admitted to the ICUs were assessed for participation. Study inclusion criteria were age $\geq 18$ y, requirement for mechanical ventilation, and inhalation therapy that was to be administered via an MDI. Exclusion criteria included lung transplant, status asthmaticus, neutropenia, and patients placed on isolation precautions due to colonization with antibiotic-resistant bacteria (eg, methicillin-resistant Staphylococcus aureus, vancomycin-resistant enterococci), Clostridium difficile, or respiratory viruses (eg, influenza $\mathrm{A}$ or $\mathrm{B}$, rhinovirus, adenovirus). The medical and surgical ICUs were each divided into 2 study groups based on geographic location and proximity to the PYXIS Medstation (CareFusion, San Diego, California) within these units. The 2 study groupings within each ICU were randomly assigned so that subjects admitted to each group would receive either shared canister therapy or single-patient canister therapy. Subjects in the shared canister group received MDI therapy from a single canister until the canister was fully discharged. Subjects assigned to the single-patient group had one MDI canister assigned per subject. Respiratory therapists followed a cleaning protocol before administration of MDI therapy for subjects assigned to both groups (Table 1).

\section{End Points and Covariates}

The end points examined were occurrence of ventilatorassociated pneumonia (VAP), hospital mortality, length of

\section{QUICK LOOK}

\section{Current knowledge}

There are no clinical data available to guide the use of shared canister delivery of MDIs in mechanically ventilated patients. Current standard of practice is to provide single-patient use MDIs to individual patients requiring inhalation therapy during mechanical ventilation.

\section{What this paper contributes to our knowledge}

Our study demonstrates that shared canister delivery is associated with similar occurrence of ventilator-associated pneumonia, hospital mortality, and length of stay and lower MDI costs compared with the current practice of single-patient MDI therapy. We also found a significantly higher occurrence of ventilator-associated events among subjects receiving shared canister therapy without a clear clinical explanation for this observation. These findings suggest that shared canister delivery of MDIs may be a cost-effective practice in mechanically ventilated patients. However, further studies examining the overall safety of shared canister use in mechanically ventilated subjects seem warranted before recommending their routine use.

stay, ventilator-associated events, and MDI costs. Ventilator-associated events included ventilator-associated conditions (VACs) and infection-related VACs. We collected important covariates, including demographics, occurrence of nosocomial infections, hospital mortality, and length of stay. Severity of illness was assessed by the Acute Physiology and Chronic Health Evaluation (APACHE) II score, ${ }^{9}$ and comorbidities were assessed with the Charlson comorbidity index score. ${ }^{10}$

\section{Definitions and Outcomes Assessment}

The definition for ventilator-associated events was taken from the published update from the Centers for Disease Control and Prevention (CDC). ${ }^{11}$ To meet the VAC definition, a mechanically ventilated subject had to have at least 2 calendar days of stable or decreasing daily minimum PEEP or $\mathrm{F}_{\mathrm{IO}_{2}}$, followed by at least $2 \mathrm{~d}$ of increased daily minimum PEEP or $\mathrm{F}_{\mathrm{IO}_{2}}$, where the increase in the daily minimum PEEP was $\geq 3 \mathrm{~cm} \mathrm{H}_{2} \mathrm{O}$ or where the increase in the daily minimum $\mathrm{F}_{\mathrm{IO}_{2}}$ was $\geq 0.20$ (or 20 percentage points in oxygen concentration). Infection-related VACs are characterized by an abnormal white blood cell count $(\geq 12,000 \mathrm{Cells} / \mu \mathrm{L}$ or $\leq 4,000 \mathrm{Cells} / \mu \mathrm{L})$ or temperature $\left(>38\right.$ or $\left.<36^{\circ} \mathrm{C}\right)$ and a new antimicrobial start. 


\section{Shared Canister Protocol for MDi Delivery in Mechanical Ventilation}

Table 1. Metered-Dose Inhaler Shared Canister Cleaning Protocol

The respiratory therapist administering MDI therapy will perform hand hygiene prior to entering the subject's room, don gloves, and follow standard precautions as appropriate. Perform cleaning of MDI canister as follows:

1. Remove appropriate MDI canister from the PYXIS Medstation System (CareFusion, San Diego, California).

2. Obtain a minimum of 4 alcohol prep pads (70\% isopropyl alcohol).

3. Thoroughly wipe:

a. MDI canister well on Aerovent collapsible holding chamber (Monaghan Medical, Plattsburgh, New York)

b. Canister tip/sides and dose counter casing as applicable

4. Allow all surfaces to air-dry prior to placing canister in well

5. After administration of the MDI therapy:

a. Remove canister from MDI canister well

b. Wipe canister tip/sides and dose counter casing thoroughly

c. Allow to air-dry

6. Do not place MDI canister in plastic bag or in pocket prior to transport to subsequent subject rooms. Simply carry cleaned canister to next subject requiring MDI treatment in the shared canister group and repeat above processes, then replace canister in the PYXIS Medstation System following administration of all prescribed MDI treatments.

7. Store shared canister in PYXIS Medstation System in the respiratory care services bin per guidelines.

For subjects assigned to single-patient MDI therapy, the same cleaning protocol was followed with the exception that the MDIs were kept in the subject's room.

MDI $=$ metered-dose inhaler

Infection-related VACs were defined so as to be likely to capture subjects with pulmonary and extrapulmonary infections of sufficient severity to trigger respiratory deterioration. The definition for probable VAP was also taken from the CDC update. ${ }^{11}$ A clinical diagnosis of VAP was defined as a new or progressive consolidation on chest radiographs plus at least 2 of the following clinical criteria: fever $>38^{\circ} \mathrm{C}$, leukocytosis or leukopenia, and purulent secretions. The presence or absence of a new or progressive radiographic infiltrate was based on the interpretation of the chest radiograph by board-certified radiologists who were blinded to the study. The diagnosis of VAP was microbiologically confirmed with either bronchoalveolar lavage or tracheal aspirate cultures demonstrating significant growth using a semiquantitative culture technique ( $\geq 10^{4}$ and $\geq 10^{5}$ colony-forming units/mL, respectively). ${ }^{12}$

The occurrence of a VAC or infection-related VAC was determined by infection prevention specialists who were blinded to subjects' study group assignment using an automated informatics surveillance system developed at Barnes-Jewish Hospital. ${ }^{13}$ The occurrence of VAP was determined by one of the investigators (MHK), who was also blinded to subjects' study group assignment.

Drug costs were based on the Red Book published by Truven Health Analytics (http://sites.truvenhealth.com/ redbook/index.html. Accessed March 11, 2016) calculated by multiplying the number of MDIs employed in each treatment group by the retail price of each MDI (albuterol $=\$ 21.64$; ipratropium $=\$ 311.87$; ipratropium/albuterol $=\$ 333.51$ ). Per Barnes-Jewish Hospital protocol, the number of MDI actuations for each treatment was 8 for albuterol, ipratropium, and ipratropium/albuterol MDIs, respectively. The MDIs employed at Barnes-Jewish Hospital contained 60 actuations/canister for albuterol, 200 actuations/canister for ipratropium, and 200 actuations/canister for ipratropium/albuterol. For subjects receiving shared MDI therapy, the cost of the MDIs was taken up by the pharmacy department for the duration of this study.

\section{Statistical Analysis and Sample Size Justification}

We estimated sample size to provide $80 \%$ power to detect a $15 \%$ difference in the rate of occurrence of ventilator-associated events between the 2 study groups. We used an $\alpha$ error of 0.05 (2-tailed). On the basis of these assumptions, 134 subjects were needed in each of the 2 study groups. We assessed for normal distributions with the Shapiro-Wilk test. Our study design resulted in an asymmetric patient randomization. Continuous variables are reported as means $\pm \mathrm{SD}$ when distributed normally or medians (interquartile range) when skewed. Differences between mean values were tested via Student $t$ test, and all other distributions were compared by the Mann-Whitney $\mathrm{U}$ test. Categorical data are summarized as proportions, and the chi-square test or Fisher exact test for small samples was used to examine differences between groups. We confirmed the results of these tests for ventilator-associated events and VAP while controlling for specific subject characteristics (age, sex, race, ICU [medical or surgical], APACHE II score, Charlson score), using multiple logistic regression analysis. All variables entered into the model were assessed for co-linearity, and interaction terms were tested. The most parsimonious model was derived using the backward manual elimination method, and the bestfitting model was chosen based on the $\mathrm{C}$ statistic. The model's calibration was assessed with the Hosmer-Lemeshow goodness-of-fit test. Results of logistic regression are presented as adjusted odds ratios with $95 \%$ confidence intervals. A $P$ value of .05 was considered statistically significant, and all analyses were 2 -sided.

\section{Results}

\section{Patients}

486 consecutive patients who required mechanical ventilation and received inhalation therapy with an MDI were evaluated (Fig. 1). Among these patients, 126 (25.9\%) were excluded due to colonization or infection with an 


\section{Shared Canister Protocol for MDi Delivery in Mechanical Ventilation}

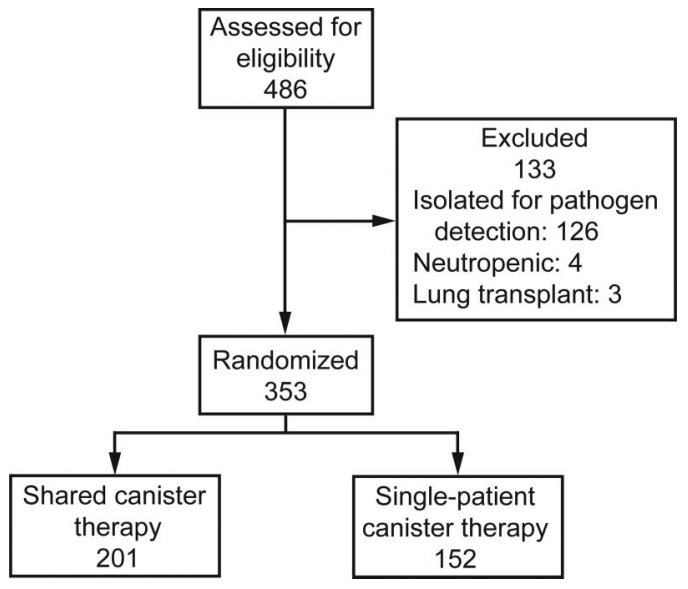

Fig. 1. Flow chart.

antibiotic-resistant bacteria or a respiratory virus. Four patients were excluded due to neutropenia, and 3 were excluded as a result of having a lung transplant. Thus, 353 subjects were included for analysis of whom $152(43.1 \%)$ received single-patient MDI therapy and 201(56.9\%) received shared MDI therapy. At the time of ICU admission, no statistically significant differences were found between the 2 treatment groups for age, sex, ethnicity, APACHE II score, or the Charlson comorbidity score (Table 2). There were statistically more surgical subjects in the shared canister group and statistically more medical subjects who received single-patient therapy.

Most subjects received albuterol MDIs (88.7\%), followed by ipratropium MDIs (36.0\%) and combined albuterol/ipratropium MDIs (21.8\%) (Table 2). The MDItype distribution was similar across study groups. Based on canister sizes employed during the study period, a mean of 7 subjects in the shared MDI group shared an albuterol canister, whereas a mean of 25 subjects shared an ipratropium or ipratropium/albuterol canister. Ninety-one subjects $(45.2 \%)$ in the shared canister group and 63 subjects (41.4\%) in the single-patient canister group received more than one medication delivered by MDI. There was no difference in the median number of MDI doses administered for the shared canister group and the single-patient canister group (17.4 [5.0-46.7] doses vs 15.8 [5.6-36.0] doses, $P=.53$ ).

\section{Ventilator-Associated Conditions}

Ten of the 353 study subjects (2.8\%) developed a ventilator-associated event, of which $3(30.0 \%)$ were infection-related VACs. Among subjects with infection-related VACs, one was classified as probable VAP and 2 as having non-pulmonary sepsis. Among the 7 VACs, 3 were attributed to worsening pulmonary edema, and one each to atelectasis, renal failure, metastatic cancer, and ARDS. In the group assigned to receive shared canister MDI therapy, 9 subjects (4.5\%) developed a ventilator-associated event; one subject $(0.7 \%)$ assigned to single-patient MDI therapy developed a ventilator-associated event (relative risk 6.806 [95\% CI 0.872-53.147, $P=.048$ ]) (Table 3). When we used multiple logistic regression analysis to control for all relevant confounders, the adjusted odds ratio assessing the relation between ventilator-associated event and treatment group assignment (receiving shared canister MDI therapy compared with single-patient therapy) was 6.931 (95\% CI 2.910-20.166, $P=.07$ ).

Twenty-one $(5.9 \%)$ subjects developed microbiologically confirmed VAP. In the group assigned to receive shared canister therapy, 14 subjects ( $7.0 \%$ ) developed VAP; 7 subjects (4.6\%) assigned to receive single-patient therapy developed VAP (relative risk 1.513 [95\% CI $0.626-$ $3.656, P=.35])$. When we used multiple logistic regression analysis to control for all relevant confounders, the adjusted odds ratio assessing the relation between VAP and treatment group assignment (receiving shared canister MDI therapy compared with single-patient therapy) was 1.484 (95\% CI $0.916-2.408, P=.41$ ). The ventilatorassociated event surveillance criteria identified none of the 21 subjects with microbiologically confirmed VAP.

\section{Other Outcomes}

The mean hospital stay, ICU stay, and duration of mechanical ventilation for the entire study group was $18.0 \pm 15.9,10.4 \pm 10.7$, and $6.0 \pm 9.4 \mathrm{~d}$, respectively. The hospital stay, ICU stay, and duration of mechanical ventilation did not differ significantly between the 2 treatment groups (Table 3). Seventy-five subjects died during their study hospitalization, yielding an overall hospital mortality rate of $21.2 \%$. No statistically significant difference in the mortality rates was found between the 2 study groups. The use of vasopressors, antibiotics, and bloodstream infections was also similar between study groups (Table 3). Total costs for MDI therapy during hospitalization were $\$ 173,770.27$ (3,304 MDIs employed) in the group receiving single-patient MDI therapy and \$130,112.28 (3,005 MDIs employed) in the group receiving shared canister MDI therapy (Table 4). This resulted in a cost savings of $\$ 43,657.99$ for subjects in the shared canister group, or $\$ 217$ per subject, due to the use of 299 fewer MDIs.

\section{Discussion}

We found that a practice of shared canister MDI inhalation therapy was associated with similar rates of VAP, hospital mortality, and length of stay but an increased risk for ventilator-associated events when compared with the usual practice of single-patient MDI therapy. MDI costs were more than $\$ 40,000$ greater in the group receiving 
Shared Canister Protocol for MDi Delivery in Mechanical Ventilation

Table 2. Baseline Characteristics at Study Enrollment

\begin{tabular}{|c|c|c|c|}
\hline Characteristics & Shared Canister Therapy $(n=201)$ & Single-Patient Canister Therapy $(n=152)$ & $P$ \\
\hline Male, $n(\%)$ & $108(53.7)$ & $86(56.6)$ & .59 \\
\hline Age, median (IQR) y & $60.7(52.4-68.8)$ & $62.9(51.4-70.7)$ & .45 \\
\hline \multicolumn{4}{|l|}{ Race, $n(\%)$} \\
\hline White & $136(67.7)$ & $100(65.8)$ & .71 \\
\hline Black & $58(28.9)$ & $44(28.9)$ & .99 \\
\hline Other & $7(3.5)$ & $8(5.3)$ & .41 \\
\hline \multicolumn{4}{|l|}{$\mathrm{ICU}, n(\%)$} \\
\hline Medical & $58(28.9)$ & $69(45.4)$ & .001 \\
\hline Surgical & $143(71.1)$ & $83(54.6)$ & .001 \\
\hline Charlson comorbidity index score, median (IQR) & $5(2-7)$ & $5(2-7)$ & .70 \\
\hline APACHE II score, median (IQR) & $14(11-18)$ & $13(11-17)$ & .25 \\
\hline \multicolumn{4}{|l|}{ MDIs administered, $n(\%)$} \\
\hline Albuterol & $181(90.0)$ & $132(86.8)$ & .35 \\
\hline Ipratropium & $71(35.3)$ & $56(36.8)$ & .77 \\
\hline Ipratropium/albuterol & $47(23.4)$ & $30(19.7)$ & .41 \\
\hline $\begin{array}{l}\mathrm{IQR}=\text { interquartile range } \\
\text { APACHE = Acute Physiology and Chronic Health Evaluation } \\
\text { MDIs = metered-dose inhalers }\end{array}$ & & & \\
\hline
\end{tabular}

Table 3. Clinical Outcomes

\begin{tabular}{|c|c|c|c|}
\hline Outcomes & Shared Canister Therapy $(n=201)$ & Single-Patient Canister Therapy $(n=152)$ & $P$ \\
\hline Ventilator-associated events, $n(\%)$ & $9(4.5)$ & $1(0.7)$ & .048 \\
\hline IVAC, $n(\%)$ & $3(1.5)$ & $0(0.0)$ & .26 \\
\hline $\mathrm{VAP}, n(\%)$ & $14(7.0)$ & $7(4.6)$ & .35 \\
\hline Hospital length of stay, median (IQR) d & $14(7-26.5)$ & $11.5(7-22)$ & .09 \\
\hline Intensive care unit length of stay, median (IQR) d & $7.3(3.4-14.6)$ & $6.1(2.7-14.5)$ & .15 \\
\hline Mechanical ventilation, median (IQR) d & $3.1(0.9-7.5)$ & $2.7(1.2-7.1)$ & .62 \\
\hline Hospital mortality, $n(\%)$ & $44(21.9)$ & $31(20.4)$ & .73 \\
\hline \multirow[t]{2}{*}{ Vasopressors, $n(\%)^{*}$} & $107(53.2)$ & $79(52.0)$ & .81 \\
\hline & $129(64.2)$ & $94(61.8)$ & .65 \\
\hline \multirow[t]{2}{*}{ Antibiotics, $n(\%)^{*}$} & $136(67.7)$ & $91(59.9)$ & .13 \\
\hline & $173(86.1)$ & $124(81.6)$ & .25 \\
\hline Bloodstream infection, $n(\%) \dagger$ & $5(2.5)$ & $5(3.3)$ & .65 \\
\hline $\begin{array}{l}\text { * Vasopressor and antibiotic administration within } 48 \mathrm{~h} \text { and } 7 \mathrm{~d} \text {, res } \\
\dagger \text { Occurrence after study enrollment. } \\
\text { IVAC }=\text { infection-related ventilator-associated condition } \\
\mathrm{VAP}=\text { ventilator-associated pneumonia } \\
\text { IQR }=\text { interquartile range }\end{array}$ & vely, after initial metered-dose inhaler therapy. & & \\
\hline
\end{tabular}

single-patient MDI therapy. Our results are unique in assessing the practice of shared canister MDI therapy in a large group of mechanically ventilated subjects.

The practice of shared canister MDI administration offers a potential solution to the discordance between MDI canister sizes and average in-patient use of these drugs. MDI canisters are designed for out-patient use and contain enough drug for several weeks of daily use. However, the average stay for most in-patients is only several days. ${ }^{14}$ Therefore, most in-patients do not use all of the MDI canister contents, an unused resource that is potentially wasted. Moreover, based on local practices at Barnes-Jewish Hospital and other BJC Healthcare hospitals, patients transitioned from the ICU to non-ICU wards usually have their ICU MDIs discarded and are prescribed new MDIs on their new ward, resulting in further waste of drug. The unused MDIs can be handled in various ways, each presenting unique problems. Upon patient discharge, some institutions dispense the partially used canisters when continuation of therapy is warranted. This practice utilizes remaining canister contents and provides a service to the patient. However, state laws often require relabeling of the 
Table 4. Metered-Dose Inhaler Costs

\begin{tabular}{|c|c|c|c|c|c|c|}
\hline & $\begin{array}{l}\text { Shared Canister } \\
\text { MDIs Used }\end{array}$ & Cost & $\begin{array}{l}\text { Single-Patient Canister } \\
\text { MDIs Used }\end{array}$ & Cost & $\begin{array}{c}\text { Inhalers } \\
\text { Saved }\end{array}$ & $\begin{array}{c}\text { Cost } \\
\text { Savings }\end{array}$ \\
\hline \multicolumn{7}{|l|}{ Albuterol (60 puffs/canister) } \\
\hline All hospital days & 2,785 & $\$ 60,267.40$ & 2,959 & $\$ 64,032.76$ & 174 & $\$ 3,765.36$ \\
\hline ICU days only & 2,188 & $\$ 47,348.32$ & 2,357 & $\$ 51,005.48$ & 169 & $\$ 3,657.16$ \\
\hline Ventilated ICU days only & 1,692 & $\$ 36,614.88$ & 1,857 & $\$ 40,185.48$ & 165 & $\$ 3,570.60$ \\
\hline \multicolumn{7}{|l|}{ Ipratropium (200 puffs/canister) } \\
\hline All hospital days & 163 & $\$ 50,834.81$ & 246 & $\$ 76,720.02$ & 83 & $\$ 25,885.21$ \\
\hline ICU days only & 118 & $\$ 36,800.66$ & 198 & $\$ 61,750.26$ & 80 & $\$ 24,949.60$ \\
\hline Ventilated ICU days only & 104 & $\$ 32,434.48$ & 186 & $\$ 58,007.82$ & 82 & $\$ 25,573.34$ \\
\hline \multicolumn{7}{|c|}{ Ipratropium/albuterol (200 puffs/canister) } \\
\hline All hospital days & 57 & $\$ 19,010.07$ & 99 & $\$ 33,017.49$ & 42 & $\$ 14,007.42$ \\
\hline ICU days only & 55 & $\$ 18,343.05$ & 97 & $\$ 32,350.47$ & 42 & $\$ 14,007.42$ \\
\hline Ventilated ICU days only & 55 & $\$ 18,343.05$ & 97 & $\$ 32,350.47$ & 42 & $\$ 14,007.42$ \\
\hline
\end{tabular}

Costs were calculated by multiplying the number of MDIs employed in each treatment group by the retail price of each MDI (albuterol, $\$ 21.64$; ipratropium, $\$ 311.87$; ipratropium/albuterol, $\$ 333.51$ ) obtained from the Red Book published by Truven Health Analytics.

drug as an out-patient prescription in this situation, presenting additional regulatory and labor burdens to pharmacy departments. Alternatively, many hospitals discard the partially used canister, deeming the risk of potential infection with reuse greater than any potential cost savings. ${ }^{15}$

Use of shared canister MDI inhalation therapy in inpatient settings has primarily been described in abstract form and poster presentations and not in peer-reviewed medical literature. Accounts are descriptive, not experimental; therefore, the strength of evidence supporting safe use is relatively weak. Early data from the 1990s suggested canister contamination rates of approximately 5\%, both with and without decontamination. ${ }^{16,17}$ At Georgia University Hospital, investigators collected 60 samples from MDI canister nozzles of nonintubated subjects before and after disinfection with alcohol and from adapter sites after disinfection. ${ }^{16}$ Cultures were positive after 5 days in 3 , 5, and 11 samples, respectively, revealing a $\geq 5 \%$ contamination rate even after disinfection. ${ }^{16}$ These authors also evaluated contamination rates of used MDIs that were decontaminated or not decontaminated with alcohol before nozzle tip culture. None of the 37 cultures were positive when decontaminated before culture, compared with 1 of $18(5.5 \%)$ that was not decontaminated. ${ }^{17}$ It is notable that these analyses were performed in one geographic location; thus, local microbial flora or infection control practices could play an important role in the authors' findings of minimal contamination.

Data after 2000 revealed findings supportive of shared canister use in nonintubated subjects. A university teaching hospital utilizing a shared canister protocol analyzed 150 cultured swabs from used MDI mouthpieces that were decontaminated with alcohol. None were positive at $72 \mathrm{~h}$, a finding that was echoed in the same analysis at a 250-bed teaching hospital. ${ }^{18,19}$ The most recent accounts of shared canister use from 2010 and beyond describe the use of one-way valve chambers in addition to decontamination with alcohol for use in nonintubated patients. A 4-hospital acute care system in Kentucky disinfected canister boots with $70 \%$ isopropyl alcohol before and after administration and used patient-specific one-way valve chambers. ${ }^{20}$ Seventy of 71 random swab samples of shared canisters were negative, with one positive culture for normal respiratory flora. Similarly, a Montana community hospital using the same decontamination and one-way valve chamber measures found no significant change in nosocomial respiratory infection rates during the 6 months before and after implementation of a shared canister program, although infection rates and the number of exposed subjects were not reported. ${ }^{21}$ Notable in these accounts are small sample sizes, which limit precision in estimating the true incidence of contamination. Additionally, healthcare workers' adherence to handwashing protocols was not considered, despite the well-documented nature of non-adherence. ${ }^{22}$

Reported cost savings from employing shared canister MDI therapy have not been thoroughly quantified. The Kentucky health system, which interchanged subjects to MDIs when possible and charged on a per-puff basis, realized a $50 \%$ reduction in oral inhaler expenditures but did not describe absolute cost savings. ${ }^{20}$ A Pennsylvania community hospital reportedly reduced annual MDI costs by $\$ 75,000$ but did not define the percentage change in costs or the cost savings attributed to shared canister use. This savings was mostly attributable to an interchange to Advair MDI from Advair dry powder inhalers, which cannot be reused. ${ }^{23}$ None of these analyses considered the potential costs of nosocomial respiratory infections acquired via contaminated canisters or other adverse outcomes associ- 
ated with the use of shared canisters. The additional cost attributable to hospital-acquired pneumonia has been estimated at $\$ 46,400$, and several such cases could easily offset the annual cost savings described with shared canister use. ${ }^{24,25}$ Another approach for reducing the costs associated with the use of MDIs would be to employ nebulization of medications like albuterol and ipratropium.

The Institute for Safe Medication Practices commented on shared canister use in 2009 but did not offer definitive recommendations, suggesting only careful protocol development and stringent adherence to decontamination. ${ }^{26}$ The Association for Professionals in Infection Control and Epidemiology has emphasized the importance of hand hygiene and disinfection to reduce sources of contact transmission when employing shared canisters and has addressed the dilemma of wasted medication due to partially used MDIs, a problem that will probably be unresolved until smaller canisters are manufactured for more resourceful use in hospitalized patients. ${ }^{27}$ In the interim, institutions should consider their volume of MDI use, local microbiological epidemiology, and the proportion of severely immunocompromised patients when deciding whether to initiate a shared canister policy. Based on the limited available data, a contamination rate of approximately $5 \%$ could be present and may be reduced with the use of a one-way valve chamber and strict adherence to infection control protocols in nonintubated patients. Our data suggest that the use of shared canister MDI inhalation therapy may be associated with minimal yet greater prevalence of ventilator-associated events and VAP and length of stay, thus negating any potential cost savings from their use.

Our study had several limitations. First, we used the CDC definition for VACs as an outcome. A number of recent studies have cast doubt on the ability of VACs to accurately predict outcome events, including hospital mortality and VAP, or to identify preventable causes of respiratory deterioration. ${ }^{12,28,29}$ The findings from this study support our earlier observation as well as those from other investigators, that the ventilator-associated event criteria are not sensitive for identifying patients with VAP. ${ }^{12,29,30}$ Moreover, we could not identify any physiologic rationale for the higher rate of ventilator-associated events among subjects receiving shared canister therapy. It is also important to note that this association was marginally significant and after correction for potential confounders was no longer found to be significant. Second, we did not obtain surveillance cultures from the subjects or the canisters. Therefore, we cannot determine whether differences in colonization with potentially pathogenic microorganisms occurred between the study groups. Third, we employed a cleaning protocol for all MDIs as part of our study. It is not clear whether our findings can be replicated at other centers utilizing different MDI utilization practices or different MDI cleaning protocols. Additionally, it is possible that adherence to the cleaning protocol could wane when therapists are overextended. Fourth, we did not evaluate all potential confounding variables that could influence the occurrence of VACs or VAP (for example, previous antibiotic exposure, re-intubation). Finally, Barnes-Jewish Hospital and BJC Healthcare have developed longstanding and robust infection prevention programs aimed at standardizing practices in the hospital and ICU settings to minimize nosocomial events. ${ }^{31,32}$

Another potential weakness of our study is that the MDI costs for subjects in the shared canister group were taken up by the pharmacy department at Barnes-Jewish Hospital for the study period. Therefore, our cost calculations do not represent the actual costs to the participants but representative costs for the 2 study groups. Additionally, our use of the 60 actuation/canister albuterol MDI probably influenced our overall costs as opposed to using a larger volume canister. It is also important to recognize that there are major logistical barriers to implementing a shared canister protocol in ventilated patients to include the canister cleaning protocol, which may require additional personnel effort and costs. Moreover, we did not directly evaluate protocol violations in our study and cannot provide any direct information on the level of compliance with the respiratory therapy shared canister protocol and clinical outcomes.

\section{Conclusions}

In summary, our findings suggest that shared canister MDI therapy may be a cost-effective approach in mechanically ventilated patients. However, further studies are required to determine the overall safety of shared canister therapy during mechanical ventilation, especially in other patient populations (eg, immune suppressed individuals) and non-ICU settings. ${ }^{33}$ In this era of increasing antimicrobial resistance, an alternative approach would be to have smaller dose single-patient MDIs for hospital use.

\section{REFERENCES}

1. Georgopoulos D, Mouloudi E, Kondili E, Klimathianaki M. Bronchodilator delivery with metered-dose inhaler during mechanical ventilation. Crit Care 2000;4(4):227-234.

2. Craven DE, Kunches LM, Kilinsky V, Lichtenberg DA, Make BJ, McCabe WR. Risk factors for pneumonia and fatality in patients receiving continuous mechanical ventilation. Am Rev Respir Dis 1986;133(5):792-796.

3. Dreyfuss D, Djedaini K, Weber P, Brun P, Lanore JJ, Rahmani J, et al. Prospective study of nosocomial pneumonia and of patient and circuit colonization during mechanical ventilation with circuit changes every 48 hours versus no change. Am Rev Respir Dis 1991;143(4 Pt 1):738-743.

4. Kollef MH, Shapiro SD, Fraser VJ, Silver P, Murphy DM, Trovillion E, et al. Mechanical ventilation with or without 7-day circuit changes: a randomized controlled trial. Ann Intern Med 1995;123(3):168174. 


\section{Shared Canister Protocol for MDi Delivery in Mechanical Ventilation}

5. Kollef MH, Prentice D, Shapiro SD, Fraser VJ, Silver P, Trovillion E, et al. Mechanical ventilation with or without daily changes of in-line suction catheters. Am J Respir Crit Care Med 1997;156(2 Pt 1):466-472.

6. Stoller JK, Orens DK, Fatica C, Elliott M, Kester L, Woods J, et al. Weekly versus daily changes of in-line suction catheters: impact on rates of ventilator-associated pneumonia and associated costs. Respir Care 2003;48(5):494-499.

7. Kollef MH, Shapiro SD, Boyd V, Silver P, Von Harz B, Trovillion E, Prentice D. A randomized clinical trial comparing an extendeduse hygroscopic condenser humidifier with heated-water humidification in mechanically ventilated patients. Chest 1998;113(3):759767.

8. Boisson C, Viviand X, Arnaud S, Thomachot L, Miliani Y, Martin C. Changing a hydrophobic heat and moisture exchanger after 48 hours rather than 24 hours: a clinical and microbiological evaluation. Intensive Care Med 1999;25(11):1237-1243.

9. Knaus WA, Draper EA, Wagner DP, Zimmerman JE. APACHE II: a severity of disease classification system. Crit Care Med 1985; 13(10):818-829.

10. Charlson ME, Sax FL, MacKenzie CR, Fields SD, Braham RL, Douglas RG Jr. Assessing illness severity: does clinical judgment work? J Chronic Dis 1986;39(6):439-452.

11. Magill SS, Klompas M, Balk R, Burns SM, Deutschman CS, Diekema $\mathrm{D}$, et al. Developing a new, national approach to surveillance for ventilator-associated events. Crit Care Med 2013;41(11):2467-2475.

12. Boyer AF, Schoenberg N, Babcock H, McMullen KM, Micek ST, Kollef MH. A prospective evaluation of ventilator-associated conditions and infection-related ventilator-associated conditions. Chest 2015;147(1):68-81.

13. McMullen KM, Boyer AF, Schoenberg N, Babcock HM, Micek ST, Kollef MH. Surveillance versus clinical adjudication: differences persist with new ventilator-associated event definition. Am J Infect Control 2015;43(6):589-591.

14. Centers for Disease Control and Prevention. Hospital Utilization. CDC Home. http://www.cdc.gov/nchs/fastats/hospital.htm. Updated Aug 20, 2012. Accessed June 24, 2015.

15. Drug Information Group. University of Illinois College of Pharmacy. http://dig.pharm.uic.edu/faq/2012/Oct/faq1.aspx. Accessed June 24, 2015.

16. Dunlevy CL, Rau JL, Roman SB. Surveillance of reservoir crosscontamination with multiple patient MDI use. Respir Care 1997 Open Forum Abstracts. http://www.rcjournal.com/abstracts/1997/ ?id=A00001076. Accessed September 1, 2012.

17. Hinson D, Rau JL. Incidence of contamination of metered dose inhaler canisters when used with multiple patients using spacer devices. Respir Care 1996 Open Forum Abstracts. http://www.rcjournal. com/abstracts/1996/?id=A00001206. Accessed September 1, 2012.

18. Sheils SG, Duncan JL, Wojciechowski WV. The common canister protocol using the Monaghan aerochamber reveals no cross-contamination and potential cost savings. Respir Care 2000 Open Forum Abstracts. http://www.rcjournal.com/abstracts/2000/?id=A00000303 . Accessed September 1, 2012.

19. Wojciechowski WV, Maddox HC, Moseley AL. Analysis of crosscontamination of metered dose inhalers when using the Respironics
Optichamber under the common canister protocol. Respir Care 2001 Open Forum Abstracts. http://www.rcjournal.com/abstracts/2001/ ?id=A00000079. Accessed September 1, 2012.

20. Siemens D, Petter S. Implementation of an oral inhaler therapeutic interchange and common canister program in a multi hospital health care system. Poster session presented at 46th ASHP Midyear Clinical Meeting; December 4-8, 2011; New Orleans, LA.

21. Caselnova DA, Kuiper R, Neuman J. Implementation of a common canister protocol for selected metered dose inhalers in a community hospital. Poster session presented at 44th ASHP Midyear Clinical Meeting; December 6-10, 2009; Las Vegas, NV.

22. Cohen MR, Smetzer JL. Shared metered dose inhalers: is crosscontamination avoidable? Hosp Pharm 2009;44(7):546-548.

23. Lamphere T. Common canister protocol: risk or reward? AARC Times 2009;46-49.

24. Eber MR, Laxminarayan R, Perencevich EN, Malani A. Clinical and economic outcomes attributable to health care-associated sepsis and pneumonia. Arch Intern Med 2010;170(4):347-353.

25. Kollef MH, Hamilton CW, Ernst FR. Economic impact of ventilatorassociated pneumonia in a large matched cohort. Infect Control Hosp Epidemiol 2012;33(3):250-256.

26. Institute for Safe Medication practices. https://www.ismp.org/news letters/acutecare/articles/20090409.asp. Accessed June 24, 2015.

27. Association for Professionals in Infection Control and Epidemiology. Practice Guidelines Committee Report. June 2013. http://apic. org/Resource_/TinyMceFileManager/APIC_Committee_Reports/ June_2013/PGC_Board_Report_-_June_2013.pdf. Accessed June 24, 2015.

28. Klein Klouwenberg PM, van Mourik MS, Ong DS, Horn J, Schultz MJ, Cremer OL, Bonten MJ, MARS Consortium. Electronic implementation of a novel surveillance paradigm for ventilator-associated events: feasibility and validation. Am J Respir Crit Care Med 2014; 189(8):947-955.

29. Lilly CM, Landry KE, Sood RN, Dunnington CH, Ellison RT 3rd, Bagley $\mathrm{PH}$, et al. Prevalence and test characteristics of national health safety network ventilator-associated events. Crit Care Med 2014;42(9):2019-2028.

30. Muscedere J, Sinuff T, Heyland DK, Dodek PM, Keenan SP, Wood $\mathrm{G}$, et al. The clinical impact and preventability of ventilator-associated conditions in critically ill patients who are mechanically ventilated. Chest 2013;144(5):1453-1460.

31. Babcock HM, Zack JE, Garrison T, Trovillion E, Jones M, Fraser VJ, Kollef MH. An educational intervention to reduce ventilatorassociated pneumonia in an integrated health system: a comparison of effects. Chest 2004;125(6):2224-2231.

32. Klompas M, Anderson D, Trick W, Babcock H, Kerlin MP, Li L, et al. The preventability of ventilator-associated events: the CDC Prevention Epicenters Wake Up and Breathe Collaborative. Am J Respir Crit Care Med 2015;191(3):292-301.

33. Larson T, Gudavalli R, Prater D, Sutton S. Critical analysis of common canister programs: a review of cross-functional considerations and health system economics. Curr Med Res Opin 2015;31(4): 853-860.

This article is approved for Continuing Respiratory Care Education credit. For information and to obtain your CRCE

(free to AARC members) visit www.rcjournal.com

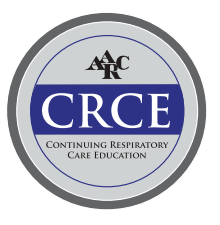

